\title{
Anti-nutrient factors affecting mineral utilization
}

By N. T. DAviEs, The Rowett Research Institute, Bucksburn, Aberdeen AB2 $9 S B$

A list of mineral elements known to be essential to animals and dietary components which under the appropriate conditions modify either their utilization or apparent requirements is shown in Table I. Clearly, detailed discussion of all of these cannot be included in this review and thus a few examples will be briefly discussed to illustrate the many types of interactions that can occur. These can be broadly classified into three categories. First, there are situations when the presence of one element in excessive concentration can modify the utilization of another essential element, usually but not exclusively at sites of absorption. Second, there are factors which, while exerting no effect on the absorption of an essential element, may affect its subsequent utilization. The best examples of this type of interaction are the goitrogens which affect the metabolism of iodine. The third class of substances which can impair mineral utilization are organic factors which can bind essential minerals to form insoluble or indigestible complexes in the lumen of the intestinal tract and prevent their absorption.

\section{Mineral-mineral interactions}

As shown in Table I the number of interactions between minerals, that have been demonstrated in laboratory animals or encountered under practical conditions in agriculture, is very large and only a few will be mentioned here. Readers particularly interested in this topic are referred to two recent reviews (Davies, 1974; Mills, 1974).

Table 1. A summary of dietary components which under the appropriate conditions modify mineral utilization or apparent requirements

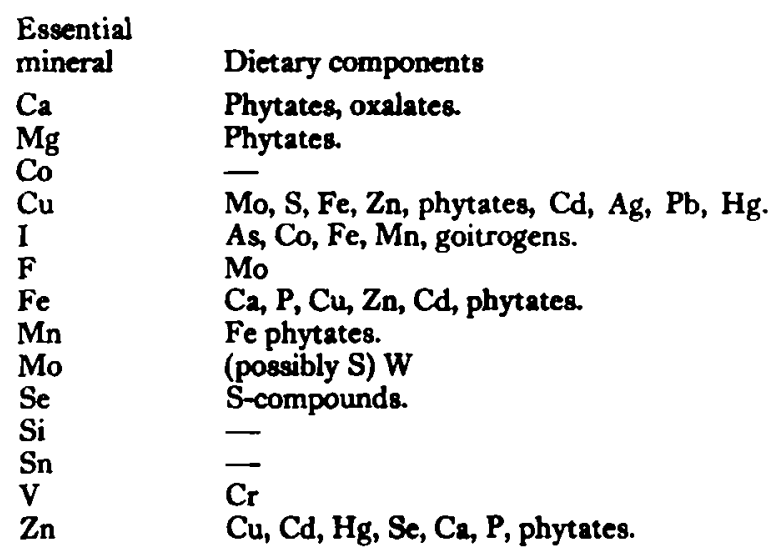

$0029-6651 / 79 / 3^{8}{ }_{3}-2103$ Sor.00 (C) 1979 The Nutrition Society. 
One type of interaction between minerals that has been commonly observed arises because elements which have similar physical and chemical properties act antagonistically to each other in biological systems. The mutual interactions between copper, zinc and cadmium amply illustrate this point. The $\mathrm{Zn}^{2+}, \mathrm{Cd}^{2+}$ and $\mathrm{Cu}^{2+}$ ions all have the same electronic structure of their valence shells and have similar tendencies to form complexes with coordination number 4 and a tetrahedral disposition of ligands around the metal. Mutual antagonisms between these elements should therefore occur due to the isomorphous replacement of one element by another at some functional site. This may be at sites of absorption, storage, excretion or at binding sites in enzymes or structural proteins.

These features are evident in the mutually antagonistic effects of excessive dietary intakes of $\mathrm{Cu}$ and $\mathrm{Zn}$. Campbell \& Mills (1974) have demonstrated that rats maintained on a diet providing marginally adequate amounts of $\mathrm{Cu}$ exhibit a range of symptoms indicative of Cu-deficiency. Conversely, pigs fed on high $\mathrm{Cu}$ rations suffer parakeratotic lesions which are symptomatic of $\mathbf{Z n}$-deficiency (Ritchie et al. 1963).

These induced deficiency states are reversible if the intake of the antagonist is increased. Thus, $\mathrm{Cu}$ supplementation of chick rations containing excessive amounts of $\mathrm{Zn}$ completely reverses the toxicity syndrome (Hill \& Matrone, 1970). Conversely Suttle \& Mills (I966) found that increased dietary intakes of $\mathrm{Zn}$ increased the tolerance of pigs to high dietary concentrations of $\mathrm{Cu}$.

Not all minerat-mineral antagonisms arise from chemical similarities between competing minerals. The clinical signs induced by a dietary excess of molybdenum in ruminants resemble those of Cu-deficiency and can be reversed by supplemental dietary $\mathrm{Cu}$. These effects are exacerbated by high dietary sulphur levels. Clearly direct chemical competition between $\mathrm{Mo}$ and $\mathrm{Cu}$ cannot account for these observations. Recent studies into the mechanisms of these complex interactions indicate that the formation of insoluble copper thiomolybdate complexes within the rumen may account for the reduced retention of dietary $\mathrm{Cu}$ (Mills et al. 1978).

All of the minerals discussed above, viz $\mathrm{Zn}, \mathrm{Cu}$, Mo and $\mathrm{S}$ are themselves essential thus illustrating that even essential dietary components may be antinutrients if present in diets in excessive amounts or in imbalanced proportion.

\section{The goitrogens}

The incidence of goitre is second only to anaemia as a disease of defective utilization of an essential mineral in man and animals and occurs in all continents of the world. While in many instances it is due principally to an iodine deficiency it is often evident even when I intakes are apparently at or above requirements. In these circumstances it is conditioned by goitrogenic substances present in diets which impair the metabolic utilization of dietary I and prevent its incorporation into the thyroid hormones.

The first observation that some foods can impair I metabolism was made by Chesney et al. (1928) who showed that rabbits consuming cabbage developed enlarged thyroid glands even when the diet contained apparently adequate 
amounts of I. However supplementation of the diets with additional I completely reversed these effects. Since this report, detailed studies have shown that virtually all varieties of Brassica as well as other species of the same family (cruciferae) exhibit goitrogenic activity. Furthermore, a number of legumes have similarly been shown to contain goitrogenic agents (reviewed by Gontzea \& Sutzescu, 1968).

Goitrogen is a generic name covering many different and unrelated compounds which can adversely affect I utilization by the thyroid. Some are relatively simple molecules or ions such as thiocyanates, isothiocyanates and cyanide whereas others can be complex glycosides, polyphenols or haemagglutinins. These widely different goitrogenic agents may be classified according to their mechanisms of action.

Thiocyanates, iso-thiocyanates and compounds which yield $\mathrm{CNS}^{-}$or $\mathrm{NSC}^{-}$in vivo. The thiocyanate and iso-thiocyanate ions have a similar ionic size as $\mathrm{I}^{-}$and can competitively inhibit I uptake into thyroid cells. In the animal body these ions may originate directly from the diet, or from glycosides of the type $\mathrm{R}-\mathrm{N}=\mathrm{C}=\mathrm{S}$ or $\mathrm{R}-\mathrm{S}-\mathrm{C}=\mathrm{N}$ which on hydrolysis either by enzymes contained within the plant or from intestinal enzymes yield $\mathrm{CNS}^{-}$or $\mathrm{NCS}^{-}$. Such glycosides have been isolated and characterized from a number of Brassica crops. Included in this class of goitrogens are substances that when ingested yield $\mathrm{CN}^{-}$since this may react either in the gut with sulphide or with thiosulphate ions in the liver under the influence of the enzyme rhodanase (thiosulphate:cyanide sulphurtransferase $E C$ 2.8.1.1) to form $\mathrm{CNS}^{-}$.

A similar goitrogen to the thiocyanate type is the glycoside, glycocheiroline found in the leaves and seeds of some Brassica crops. On hydrolysis this glycoside yields 3-methyl-sulphonyl-propyl-isothiocyanate (cheiroline) which has similar but even more potent anti-thyroid properties than simple thiocyanates.

Since the mechanism of action of this type of goitrogen involves competition for $I^{-}$uptake by thyroid cells, their effects are completely reversible if excess $I$ is supplied in the diet.

Thio-oxazolidone (goitrin). In 1949 Astwood et al. investigated the goitrogen present in yellow turnip and found its activity, unlike that of the thiocyanate type, was not fully reversible by increasing dietary $I$ intake. The agent responsible, termed 'goitrin' was subsequently identified as L-5-vinyl-thio-oxazolidine. The goitrogenic activity of most Brassica seeds and rapeseed can largely be accounted for by the presence of this compound bound as a thioglycoside ('progoitrin'). In the presence of a thioglycosidase, progoitrin hydrolyses and releases 2-hydroxy-3butenyl-isothiocyanate which rearranges to form the active goitrogen 5-vinyl-thiooxazolidone. Many similar goitrogens have been identified in Brassica crops and it is thought that their mechanism of action involves inhibition of the iodination of tyrosine presumably by inhibition of the thyroidal peroxidase (reviewed by Underwood, 1978).

Polyphenols. Another class of compounds found to exert goitrogenic activity are polyphenols, naturally present in some plants, which are capable of forming iodinated derivatives. These may compete with tyrosine for iodination and thus depress the synthesis of thyroid hormones. The anti-thyroid action exerted by 
peanuts for example can be accounted for by the presence of a sulphur-free glycoside, arachidoside, present in the red-coloured peripheral tegument (Gontzea \& Sutzescu, 1968).

Haemagglutinins. Soya beans have been shown to possess goitrogenic activity although their anti-thyroid activity differs markedly from that of the agents described above in that it is characterized by intensive uptake of I uptake into the thyroid. The agents responsible for 'soya-goitre' are thought to be the haemagglutinins which impair the entero-hepatic circulation of thyroid hormones. Thus studies in both rat (Albert \& Keating, 1952) and man (Pinchera et al. 1965) have shown that circulating thyroid hormones are readily secreted and reabsorbed across the intestine. The inhibition of reabsorption of the secreted hormones by the haemagglutinins leads to an increased demand for I by the thyroid gland.

In view of these observations further studies are needed to determine whether other legumes containing haemagglutinins may similarly possess goitrogenic activity.

\section{Organic factors which bind minerals}

Oxalic acid. The importance of oxalic acid in limiting the utilization of dietary $\mathrm{Ca}$ was first realized in 1918 when McClugage \& Mendel showed that dogs retained less $\mathrm{Ca}$ from spinach than carrots. Since these observations many studies have been made with laboratory animals and human subjects showing that dietary $\mathrm{Ca}$ is poorly utilized from oxalate-rich foods.

Oxalic acid (or its salts) is widely distributed in the plant kingdom although its nutritional significance is limited to relatively few plants and forages. It is a dicarboxylic acid which forms an insoluble calcium salt with 2 1: 1 molar stoichiometry. When this is formed in the intestine a fraction of dietary $\mathrm{Ca}$ is rendered unavailable for absorption. In view of this, the importance of the oxalate content of an individual plant product in limiting total dietary $\mathrm{Ca}$ availability is of significance only when the ration, oxalate: $\mathrm{Ca}$ is greater than $\mathrm{I}$, since under these circumstances the oxalate has the potential to complex not only the $\mathrm{Ca}$ contained in the plant but also that derived from other food sources. Plants of nutritional importance to man which contain oxalate: $\mathrm{Ca}$ ratio in excess of $\mathrm{I}$ include rhubarb $(8 \cdot 50)$, spinach $(4 \cdot 30)$, potato $(1 \cdot 60)$, beetroot $(5 \cdot 10)$, cocoa $(2 \cdot 6)$, tea $(1 \cdot 13)$ and coffee $(3 \cdot 90)$.

In ruminants oxalic acid is of only minor significance as an anti-nutritive factor since ruminal micro-flora can readily metabolize soluble oxalates and to a lesser extent even insoluble $\mathrm{Ca}$-oxalate.

While the importance of the anti-nutritive activity of oxalic acid has been recognized for over 50 years it may be a subject of interest to nutritionists in the future. Increasing research activity is being directed towards the development of 'novel' food sources using protein of bacterial or fungal origin. Some species of these organisms can produce abundant quantities of oxalic acid and may contain in excess of $5 \circ \mathrm{g} / \mathrm{kg}$ DM (Wilson \& Wilson, 1961). Clearly the oxalate contents of any 'new' foods intended for use by man or non-ruminant domestic animals should be thoroughly investigated. 
Phytic acid. (a) Effects on Ca. Phytic acid (myo-inositol 1,2,3,4,5,6-hexakis inositol dihydrogen phosphate) is a phosphorous storage compound ubiquitously distributed in the plant kingdom, being found in all cereals, many legumes and nuts and a few tubers and roots. Its identification as an anti-nutritional factor impairing mineral utilization followed the observations that consumption of cereal-rich diets, low in Vitamin D resulted in poor skeletal mineralization in dogs (Mellanby, 1921). Subsequent studies with rats demonstrated a clear correlation between the phytic acid content of different cereals and the severity of their rachitogenic effects (Bruce \& Callow, 1934). The rickets-producing effects of phytate are to this day not fully understood, but appear to be due in part to the poor availability of phytate phosphorus and partly to the ability of phytate to bind $\mathrm{Ca}$ to form an insoluble complex from which $\mathrm{Ca}$ is unavailable for absorption. These two actions result in an elevated Vitamin D requirement.

Numerous balance studies have demonstrated that consumption of phytate-rich foods similarly results in impaired $\mathrm{Ca}$ absorption in man and these observations led directly to the programme of fortification of UK flours with $\mathrm{Ca}$ in 1943 .

The importance of the possible rachitogenic effects of dietary phytate has again been of interest to human nutritionists following the recent finding of a high incidence of rickets in children born to Asian immigrant parents in a number of cities in the UK. In a series of elegant studies, Dunnigan and his associates in Glasgow have demonstrated a clear association between the incidence and severity of rickets in this section of the population and the consumption of phytate-rich chapatti-flour. (Dunnigan, 1977). However, it must be pointed out that, as yet, the precise role if any of phytate in the aetiology of 'Asian rickets' has yet to be established.

(b) Effects on Fe. Following demonstration of its effects on Ca metabolism, phytate was shown to adversely affect iron utilization in both experimental animals (Fuhr \& Steinbock, 1943) and man (Widdowson \& McCance, 1943). In balance trials in man, the latter authors showed that subjects consuming phytate-rich brown bread made from $92 \%$ extracted flour absorbed only $1 \%$ of dietary iron compared with $7 \cdot 3-12.5 \%$ when low-phytate, white bread was consumed. These and similar studies led to the fortification of UK flours with iron in 1956. Since these initial observations many studies using isotopic techniques have shown that the addition of sodium phytate to white bread markedly impaired iron absorption indicating that the poor utilization of this element from high extraction rate cereal products is due at least in part to their high phytate contents.

(c) Effects on $Z n$. The realization that phytic acid could adversely affect $\mathrm{Zn}$ utilization followed the observation that the requirement for this trace element by pigs and poultry is dependent upon the protein sources in the diets. O'Dell \& Savage (1957) for example, showed that the $\mathrm{Zn}$ requirement for poultry was higher when a cereal and soya-bean based diet was offered than when casein was used as the protein source. During the 1960 s these observations were confirmed and extended by many workers who showed that phytic acid was the agent responsible (reviewed by Davies, 1977). 
The mechanism by which phytate impairs $\mathrm{Zn}$ utilization is due to its ability to complex $\mathrm{Zn}$ (and $\mathrm{Ca}$ ) at the $\mathrm{pH}$ encountered in the intestine to form an insoluble $\mathrm{Zn}$-Ca-phytate complex from which $\mathrm{Zn}$ is unavailable for absorption.

Few studies have been made of the effects of dietary phytate on $\mathrm{Zn}$ availability in man although Reinhold et al. (1975) have shown that the addition of purified sodium phytate to bread made from an otherwise low-phytate flour resulted in increased faecal $\mathrm{Zn}$ excretion. When the same subjects consumed a phytate-rich unleavened bread made from high extraction flour, faecal $\mathrm{Zn}$ losses were even greater and two of the three subjects were in negative $\mathrm{Zn}$ balance.

The exact quantitative relationships between dietary concentrations of $\mathrm{Zn}, \mathrm{Ca}$ and phytate which give rise to impaired $\mathrm{Zn}$ absorption have yet to be fully investigated. However, in a recent study, (N. T. Davies \& S. E. Olpin, unpublished results) showed that rats consuming diets in which the molar ratio of phytate: $\mathrm{Zn}$ exceeded I 5 had significantly lower plasma $\mathrm{Zn}$ concentrations than controls receiving a phytate-free diet of similar $\mathrm{Zn}$ content. Ratios of $\mathbf{2 5}$ or greater resulted in impaired growth rates.

The significance, if any, of these findings to man has yet to be established although many components of our diets contain phytate and $\mathrm{Zn}$ in ratios in excess of 15 (Davies, 1977). These include brown bread, many breakfast cereals, peas, beans and potatoes. Of possible significance in the future is the high phytate content of soya-based textured vegetable protein (TVP), meat analogues and substitutes. In a recent study of the $\mathrm{Zn}$ and phytate contents of 19 commerciallyavailable TVP products, the phytate: $\mathrm{Zn}$ ratio ranged from $3 \mathrm{I}-43$. Furthermore, when these products were used as the protein source in diets offered to young rats, growth rates and plasma $\mathrm{Zn}$ concentrations were significantly lower than those of rats maintained on a phytate-free diet of similar $\mathrm{Zn}$ concentrations. Addition of supplemented $\mathrm{Zn}$ either in the diet or drinking water overcame these deleterious effects (N. T. Davies \& H. Reid, unpublished results; N. T. Davies \& S. E. Olphin, unpublished results).

Since it is probable that the average daily $\mathrm{Zn}$ intake by $\mathrm{UK}$ citizens at present only just meets the WHO (1973) recommended requirement for this trace element, (Davies, 1977) and that at present nearly half of our $\mathrm{Zn}$ is supplied by meat products, from which $\mathrm{Zn}$ is readily available, replacement of a significant fraction of meat by phytate-rich soya-based analogues may well result in an increased incidence of marginal $\mathrm{Zn}$-deficiency states in some sections of the population.

(d) Other trace elements. In addition to its effects on $\mathrm{Ca}, \mathrm{Fe}$ and $\mathrm{Zn}$ a few reports have indicated that phytate may adversely affect the availability of many other essential minerals. Seelig (1964) demonstrated that phytate adversely affected $\mathrm{Mg}^{2+}$ utilization and Davies \& Nightingale (1975) showed reduced retention of $\mathrm{Cu}$ and $\mathrm{Mn}$ in rats consuming phytate-supplemented diets. In view of these findings the nutritional significance of dietary phytate in relation to the essential metals needs further study. It seems likely that this agent under the appropriate dietary conditions, may promote a nutritional deficiency of any of these essential metals depending upon which first becomes limiting in the diet. 
Fibre

Another factor in foods of plant origin which may adversely affect utilization of dietary minerals is fibre. Recent studies from Iran by Reinhold and his co-workers (reviewed by Reinhold et al. 1976) have provided evidence that some of the fibre constituents of fibre-rich, high extraction flours can strongly bind $\mathrm{Zn}, \mathrm{Ca}$ and $\mathrm{Fe}$ and thus prevent their absorption.

These studies were initiated following the observation that the incidence of zinc deficiency states and anaemia were much higher in rural populations than in city dwellers even though the $\mathrm{Zn}, \mathrm{Ca}$ and $\mathrm{Fe}$ intakes of the former were greater. In both cities and villages most of the protein and energy of the diets are supplied by wheat bread, but whereas in the cities the bread is leavened and made from low extraction flour $(70-80 \%)$ that of the villagers is unleavened and made from wholemeal flour approaching 100\% extraction. This bread contains almost all the fibre and phytate of the original grain, whereas the city bread contains only one third of the original fibre and one sixth of the phytate.

From a series of balance trials and chemical studies Reinhold et al. (1976) have concluded that under some circumstances, fibre may be of equal, or even greater, importance than phytate in limiting $\mathrm{Zn}, \mathrm{Ca}$ and $\mathrm{Fe}$ availability.

While results from animal studies have failed to substantiate these effects of fibre (Davies et al. 1976) increased consumption of high extraction cereal products results in elevated intakes of fibre and phytate both of which may adversely affect mineral utilization.

\section{Conclusion}

From this brief review it is clear that much research is still needed in this field of anti-nutritional factors affecting mineral utilization. New food products such as soya-based TVP, and proteins of fungal and bacterial origin are increasingly being considered as alternatives to traditional foods. It is essential that these are systematically evaluated both for their total mineral contents and for factors which may adversely affect mineral utilization. This is particularly true if they are to replace foods which currently contribute significant quantities of minerals in available forms. Finally with the increasing awareness of the essentiality of many elements hitherto considered either toxic or non-essential e.g. chromium, vanadium, tin, nickel and silicon (Mertz, 1974) investigations should be directed towards identifying possible factors, both known and as yet undiscovered, which may affect their metabolic utilization.

\section{REFERENCES}

Albert, A. \& Keating, F. R. (1952). Endocrinology $51,427$.

Astwood, E. B., Greer, A. M. \& Ettlinger, G. E. (1949). F. biol. Chem. 181, 121.

Bruce, H. M. \& Callow, R. K. (1934). Biochem. F. 28, 517.

Campbell, J. K. \& Mills, C. F. (1974). Proc. Nutr. Soc., 33, 15 A.

Chesney, A. M., Clawson, T. A. \& Webster, B. (1928). Bull. Fohn Hopkins Hosp. 43, 261.

Davies, N. T. (1974). Proc. Nutr. Soc. 33, 293.

Davies, N. T. (1977). In Proc. Symp. 'Child Nutrition and its relation to mental and physical development', p. 21. London: Kellogg Co. Great Britain. 
Davies, N. T., Hristic, V. \& Flett, A. A. (1976). Nutr. Rep. int. 15, 207.

Davies, N. T. \& Nightingale, R. (1975). Br. F. Nutr. 34, 243.

Dunnigan, M. G. (1977). In Proc. Symp. "Child Nutrition and its relation to mental and physical development', p. 43. London: Kellogg Co. Great Britain.

Fuhr, I. \& Steinbock, H. (1943). F. biol. Chem. 147, 59.

Gontzea, I. \& Sutzescu, P. (1968). Natural Anti-nutritive Substances in Foodstuffs and Forages. Basel: S. Karger.

Hill, C. H. \& Matrone, G. (1970). Fedn Proc. Fedn Am. Socs exp. Biol. 29, 1474.

McClugage, H. B. \& Mendel, L. B. (1918). Y. biol. Chem. 35, 353.

Mellanby, E. (1921). Spec. Rep. Ser. med. Res. Coun. 61, I.

Mertz, W. (1974). Proc. Nutr. Soc. 33, 307.

Mills, C. F. (1974). In Proc. 2nd Int. Symp. on Trace Element Metabolism in Animals - 2, p. 79, [W. G. Heokstra, J. W. Suttie, H. E. Ganther and W. Mertz, editors]. Baltimore: University Park Press.

Mills, C. F. (1974). In Proc. 2nd Int. Symp. on Trace Element Metabolism in Animals - 2, p. 79, Int. Symp. on Trace Element Metabolism in Man and Animals - 3, p. 150, [M. Kirchgessner, editor]. Freising-Weihenstephan: Arbeitskreis Fur Tierernahrungs forschung Weihenstephan.

O'Dell, B. L. \& Savage, J. E. (1957). Fedn Proc. Fedn Am. Socs exp. Biol. 16, 394.

Pinchera, A., MacGillivray, M. H., Crawford, J. D. \& Freeman, A. G. (1965). Newo Engl. J. Med. 273,83 .

Reinhold, J. G., Faradji, B., Abadi, P. \& Ismail-Beige, F. (1976). In Trace Elements in Human Health and Disease, Vol. I. Zinc and Copper, [A. S. Prasad, editor]. New York: Academic Press.

Reinhold, J. G., Nasr, K., Larhimgarzadeh, A. \& Hedayati, H. (1975). Lancet i, 282.

Ritchie, H. D., Lueke, R. W., Baltzer, B. V., Miller, E. R., Ullrey, D. E. \& Hoefer, J. A. (1963). F. Nutr. 79, 17 .

Seelig, M. S. (1964). Am. F. clin. Nutr. I4, 342.

Suttle, N. F. \& Mills, C. F. (1966). Br. F. Nutr. 20, 135 .

Underwood, E. W. (1978). Trace Elements in Human and Animal Nutrition, $4^{\text {th edn. New York }}$ \& London: Academic Press.

W.H.O. (1973). Tech. Rep. Ser. Wld Hith Org. No. 522, p. 13.

Widdowson, E. M. \& McCance, R. A. (1943). Lancet i, $5^{88 .}$

Wilson, B. J. \& Wilson, C. H. (196I). Amer. J. vet. Res. 22, 96 I. 